\title{
A Divided Mind: Observations on the Conscious Properties of the Separated Hemispheres
}

\author{
Joseph E. LeDoux, PhD, Donald H. Wilson, MD, \\ and Michael S. Gazzaniga, PhD
}

\begin{abstract}
Each cerebral hemisphere in Patient P. S., a callosum-sectioned patient, appears to possess mental properties deserving of conscious status. The observations seem to answer many questions concerning the issue of whether the mechanisms of consciousness can be split and doubled by split-brain surgery. As $P$. S. is the first split-brain patient clearly to possess double conscious processes as well as the first with extensive bilateral linguistic skills, the observations suggest that the special nature of human conscious experience is closely tied to linguistic processes.
\end{abstract}

LeDoux JE, Wilson DH, Gazzaniga MS: A divided mind: observations on the conscious properties of the separated hemispheres. Ann Neurol 2:417-421, 1977

Contemporary interest in the neuropsychological mechanisms of human consciousness was stimulated in the 1960 s by observations of patients who had undergone cerebral commissurotomy in an effort to control the interhemispheric spread of epileptic seizure activity [7-10]. These split-brain studies demonstrated that each cerebral hemisphere could process information outside the realm of awareness of the other half-brain, and thereby suggested that brain bisection produces a state of double consciousness.

Speculation concerning double conscious mechanisms in split-brain patients has taken two forms. One is the notion that each cerebral hemisphere in man has evolved a separate cognitive style and mode of information processing $[1,5,11,15,16,24,25,30]$. The other, which we address here, is the more basic question of whether the mechanisms of human consciousness are actually split following brain bisection $[3,5$, $18,19,26-29,33]$.

As it is relatively easy to assess the nature and limits of cognition and consciousness in the left, speaking hemisphere, the challenge has always been to determine the conscious properties of the mute half-brain. Studies to date $[2,4,17,19-23,32]$ have not conclusively shown that the separated right half-brain possesses some of the more abstract qualities of mental life. Consequently, the view [26] that the mute hemisphere is an equal partner with the left in terms of conscious processes has been widely criticized on philosophical and empirical grounds [3, 18, 33]. As Mackay [19] has noted, until it can be shown that each separate half-brain has its own independent system for assigning values to events and for setting goals and response priorities, the split brain cannot be viewed as a split mind.

The question of whether the essence of human consciousness can be represented bilaterally in the splitbrain patient has so far remained unanswered. The following observations on a new patient, Patient P. S., may help to resolve the issue. For the frst time, it has been possible to ask subjective questions of the separated right hemisphere and to witness self-generated answers from this mute half-brain. This opportunity was made possible by the fact that linguistic representation in the right hemisphere of our patient is greater than has been observed in any other split-brain patient. In addition to an extensive capacity for comprehending written and spoken language, the right hemisphere, though unable to generate speech, can express its mental content by arranging letters to spell words [12].

The observations that follow are not meant to suggest the normal properties of all right hemispheres. The extensive bilateral linguistic representation in this special case allows us to observe what can exist, rather than what necessarily exists normally.

\section{Material and Method}

P. S., a right-handed boy, experienced a series of severe convulsions at about 2 years of age, with a seizure focus identified in the left temporal region by electroencephalography. Following this early activity he apparencly developed
From the Department of Neurology, Cornell Medical School, New York, NY, and the Department of Neurosurgery, Dartmouth Medical School, Hanover, NH
Accepted for publication May 23, 1977.

Address reprint requests to $\mathrm{Dr}$ Gazzaniga, Department of Neurology, Cornell Medical Center, 525 E 68th St, New York, NY 10021 
normally until age 10 , when gencralized seizures recurred spontaneously and became intractable. In January, 1976, he was operated on for complete surgical section of the corpus callosum. A complete medical history has been published elsewhere [31]; this report deals exclusively with psychological evaluation of the conscious properties of the patient's separated hemispheres.

All tasks involved the lateralized presentation of visual stimuli. The subject was seated about $1 \mathrm{~m}$ from an opaque screen and instructed to fixate on a dot in the center of the screen. By means of a standard slide projector fitted with an electronic shurter, stimuli were presented to the right or left of fixation for 100 to $150 \mathrm{msec}$.

The first two tests involved the scaling of words. These tests were aimed at determining whether each hemisphere has its own independent system for assigning subjective values to environmental events.

In the first test, following lateralized presentation of a word, the subject was required to select (by pointing) the number from 1 to 7 that represented how he felt about that word. He was previously instructed that 1 represented "good" and 7 "bad," with points in between indicating gradations of "goodness" or "badness." In all, sixteen words were scaled (Table 1). The words used were selected either because they have been empirically decermined to be amenable to "good/bad" scaling [14] or because of their personal significance to the patient. The words of the latter category included "Paul" (his name), "Liz" (his girlfriend's name), "Fonz" (a television character he talks about), and "car" (another frequent word in his vocabulary).

In the second scaling test, the words (Table 2) were all of the personal type. These words, which were chosen on the basis of previous conversations with the subject, were scaled in a manner similar to the previous test except that a fivepoint scale was used. On each trial the subject was asked, "How much do you like blank?" Subsequently, a word was lateralized and he was required to select by pointing to one of the five points of the scale: "like very much," "like," "undecided," "dislike," or "dislike very much."

The final test involved a series of questions directed to the right hemisphere. These questions were aimed at further evaluating whether this patient's mute half-brain possesses what we regard as some of the essential qualities of human consciousness, including a sense of self, a sense of the furure, goals and aspirations, feelings, and personal preferences. In addition, we were interested in having the right hemisphere generate its own responses from an unrestricted population of possibilities. To do this we capitalized on the patient's unique ability among split-brain patients to respond to right hemisphere questions by arranging letters to spell words.

At each trial the examiner asked a subjective question in which the key word or words were replaced by the word blank. Subsequently, the missing word or words were lateralized, and the patient was asked to spell his answer. To do this he was provided with two complete alphabets made up of Scrabble letters. The specific questions included the following. "Who blank?" The key words lateralized to the right hemisphere on this trial were "are you?" "Would you spell the name of your favorite blank?" This question was used on three trials directed to the right hemisphere. The key words on these trials were "girl," "person," and "hobby." The right hemisphere was also asked, "If you had your choice, what blank. would you pick?" The key word on this trial was "job." Another question asked of the right hemisphere was "What is blank?" "Tomorrow" was

Table 1. Word Rating on Good/Bad Scale ${ }^{\text {a }}$

\begin{tabular}{|c|c|c|c|c|c|c|c|c|c|c|}
\hline Word & (Good) & 1 & 2 & 3 & 4 & 5 & 6 & 7 & (Bad) & $\begin{array}{l}\text { Right/ } \\
\text { Left } \\
\text { Spread }\end{array}$ \\
\hline Nice & & $\mathrm{L}$ & & $\ldots$ & 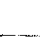 & & $\mathbf{R}$ & & & 5 \\
\hline Car & & $\mathrm{L}, \mathrm{R}$ & & & & & & & & 0 \\
\hline War & & & & $\mathrm{L}$ & & & & $\mathrm{R}$ & & 4 \\
\hline Kiss & & $\mathrm{L}$ & R & & & & & & & 1 \\
\hline Devil & & & 1. & & $\mathrm{R}$ & & & & & 2 \\
\hline Money & & $\mathrm{L}, \mathrm{R}$ & & & & & & & & 0 \\
\hline Mother & & $\mathrm{L}$ & & . & - & & $\mathrm{R}$ & & & 5 \\
\hline Sex & & $\mathrm{L}$ & & & & & $\mathrm{R}$ & & & 5 \\
\hline Vomit & & & & & & $\mathrm{L}, \mathrm{l}$ & & & & 0 \\
\hline Paul & & $\mathrm{L}_{\ldots}$ & & & & & & $\mathrm{R}$ & & 6 \\
\hline Fonz & & $\mathrm{L}_{\ldots}$ & & & & & & $\mathrm{R}$ & & 6 \\
\hline $\mathrm{Liz}$ & & $\mathrm{L}$ & & $\mathbf{R}$ & & & & & & 2 \\
\hline Sunday & & & & & & & & L & & -2 \\
\hline Truth & & & & & $\mathbf{R}$ & & & & & 1 \\
\hline Hate & & & & & & $\mathrm{L}_{-}$ & & $\mathrm{R}$ & & 2 \\
\hline Love & & $\mathrm{L}_{-}$ & & & $R$ & & & & & 3 \\
\hline
\end{tabular}

aThe right hemisphere ratings $(\mathrm{R})$ were consistently more negative than the left hemisphere ratings ( $L$ ). This is indicated in the last column, which shows the difference becween the left and right ratings. Because the left rating was always subtracted from the right rating, a positive value in the last column is indicative of a more negative rating by the right hemisphere. 
Table 2. Word Rating on Preference (LikelDislike) Scale a

\begin{tabular}{|c|c|c|c|c|c|c|}
\hline Word & LVM & $\mathrm{L}$ & $\mathrm{U}$ & $\mathrm{D}$ & DVM & Right/Left Spread \\
\hline TV & $\mathrm{L}$ & $\mathrm{R}$ & & & & 1 \\
\hline School & & $\mathrm{L}, \mathrm{R}$ & & & & 0 \\
\hline Drafting & $R$ & $L$ & & & & -1 \\
\hline Home & $\mathrm{L}, \mathrm{R}$ & & & & & 0 \\
\hline Church & $\mathrm{L}, \mathrm{R}$ & & & & & 0 \\
\hline Mom & $\mathrm{L}, \mathrm{R}$ & & & & & 0 \\
\hline Dad & $\mathrm{L}, \mathrm{R}$ & & & & & 0 \\
\hline Sex & & $\mathrm{L}, \mathrm{R}$ & & & & 0 \\
\hline Vermont & & & L, R & & & 0 \\
\hline $\mathrm{Liz}$ & & $\mathrm{L}, \mathrm{R}$ & & & & 0 \\
\hline Nixon & & & & $\mathrm{R}$ & $\mathrm{L}$ & -1 \\
\hline Beer & & & $\mathrm{L}, \mathrm{R}$ & & & 0 \\
\hline Paul & $\mathrm{L}, \mathrm{R}$ & & & & & 0 \\
\hline Police & & $\mathrm{L}, \mathrm{R}$ & & & & 0 \\
\hline Fonz & $\mathrm{L}, \mathrm{R}$ & & & & & 0 \\
\hline Dope & & $\mathrm{R}$ & $-\ldots$ & $\cdots$ & $\mathrm{L}$ & -3 \\
\hline
\end{tabular}

${ }^{a}$ The right $(\mathrm{R})$ and left ( $\mathrm{L}$ ) hemisphete ratings were strikingly consistent on this test. As can be seen in the last column, in only one instance did the hemispheres differ by more than one scale value. For a majority of the words (12 of 16$)$, the hemispheres generated the same rating.

$\mathrm{LVM}=$ like very much; $\mathrm{L}=$ like; $\mathrm{U}=$ undecided $\mathrm{D}=$ dislike; $\mathrm{DVM}=$ dislike very much.

lateralized on this trial. Finally, each hemisphere was separately asked, "In one word, how would you describe your blank?" The missing word here was "mood."

\section{Results}

The results of the first scaling test are presented in Table 1. It is clear that many of the words elicited quite different evaluations from the two hemispheres. In addition, the right hemisphere rating was consistently higher (closer to the "bad" end of the scale) than the left rating. The results of the second scaling test, which was administered approximately one month after the first, are given in Table 2. The separate ratings by the hemispheres were strikingly consistent.

The right half-brain spelled "Paul" in response to the question "Who are you?" When requested to spell his favorite girl, the right hemisphere arranged the Scrabble letters to spell "Liz." The right hemisphere spelled "car" for his favorite hobby. When the right hemisphere was asked to spell his favorite person, the following was generated: "Henry Wi Fozi." (Henry Winkler is the actor who plays Fonzie.) The right hemisphere generated "Sunday" in response to the question "What is tomorrow?" When asked to describe his mood, the right hemisphere spelled out "good." Later, in response to the same question, the left spelled "silly." Finally, the right hemisphere spelled out "automobile race" as the job he would pick. This contrasts with the frequent assertion of the left hemisphere that he will be a "draftsman." In fact, shortly after the test session, when asked what he would like to do for a living, the left hemisphere said,
"Oh, be a draftsman, I guess." Although hand use was not dictated, the left hand dominated the spelling responses of the right hemisphere, receiving some occasional support from the right hand. Finally, it should be noted that on each of these right hemisphere trials the patient was unable to name the lateralized information, thus confirming that the left hemisphere did not have access to the critical information.

\section{Discussion}

Since the conscious properties of the left hemisphere are obvious through a subject's verbal behavior, our main concern has been with the silent inhabitant of the right side of the cranium. In this regard, we have found that the right hemisphere in this patient has a sense of self, for it knows the name it collectively shares with the left. The right hemisphere has feelings, for it can describe its mood. The right hemisphere has a sense of who it likes and what it likes to do. The right hemisphere has a sense of the future, for it knows what day tomorrow is. The right hemisphere has aspirations and goals for the future, for it can describe its occupational choice.

It is important to reemphasize that these responses were self generated by the right hemisphere from a set of infinite possibilities. The only aid provided to the right hemisphere was the two complete alphabets from which he could select letters at will. The fact that the mute half-brain could generate a completely personal answer to ambiguous, subjective questions demonstrates that this patient's right hemisphere has 
its own independent response priority-determining mechanism.

These observations suggest that P. S.'s right hemisphere has a distinct consciousness. However, is that conscious awareness really different from that of its skull mate? Consider the responses of the two hemispheres on the word rating tests. The results of the first test demonstrated that each hemisphere can possess its own unique system for assigning subjective values to environmental events (see Table 1). It is of interest here that the right hemisphere ratings were consistently and substantially more negative than those of the left. It is as if the right hemisphere was in a "bad mood" relative to the left. In contrast, the results of the second test, administered at a later date, demonstrated that the half-brains can have largely overlapping opinions and values (see Table 2). Yet the degree of overlap observed-which is not surprising, given the extent to which the hemispheres share the same life experiences-highlights the subjective disparity that can exist between the hemispheres, as observed in the previous test.

These observations seem to answer some of the earlier criticisms [3,18, 19, 33] of the notion that human conscious processes can be doubled by cerebral commissurotomy. Each hemisphere in P. S. has a sense of self, and each possesses its own system for subjectively evaluating current events, planning for future events, setting response priorities, and generating personal responses.

Cerrain correlates of the various psychological responses obtained at different test sessions in this study were of interest. On a day that this boy's left and right hemispheres equally valued himself, his friends, and other matters, he was calm, tractable, and appealing. On a day when testing indicated that the right and left sides disagreed on these evaluations, the boy became difficult to manage behaviorally. It is as if each mental system could read the emotional differences harbored by the other. When they were discordant, a feeling of anxiety, which appeared to be read out by hyperactivity and general aggression, was engendered. This clear example of surgically produced psychological dynamism, seen for the first time in P. S., raises the question whether such processes are active in the normal brain, where different mental systems, using different neural codes, coexist within and between the cerebral hemispheres $[6,15]$.

Finally, it would appear that the presence of a rich linguistic system is a reliable correlate, and perhaps a necessary prerequisite, to some of the richer aspects of mental life. While it is possible that the conscious properties observed in P. S.'s right hemisphere are spuriously associared with linguistic sophistication, the fact remains that in all other split-brain patients, when linguistic sophistication is lacking in the right hemisphere, so too is the evidence for consciousness.

Supported by US Public Health Service Grant 25643.

\section{References}

1. Bogen JE: The other side of the brain: II. an appositional mind. Bull Los Angeles Neurol Soc 34:135-162, 1969

2. Bogen JE, Gazzaniga MS: Cerebral commissurotomy in man: minor hemisphere dominance for certain visuo-spatial functions. J Neurosurg 23:394-399, 1965

3. Eccles J: The brain and unity of conscious experience (19)th Arthur Stanley Eddington Memorial Lecturc). Cambridge, Engl, Cambridge University Press, 1965

4. Franco L, Sperry RW: Hemisphere lateralization for cognitive processing of geometry. Neuropsychologia 15:107-113,1977

5. Gazzaniga MS: One brain-two minds? Am Sci 60:311-317, 1972

6. Gazzaniga MS: Biology of memory, in Rosenzweig M, Bennett $M$ (eds): Neuroscience: A Review. Cambridge, MA, MIT Press, 1976

7. Gazzaniga MS, Bogen JE, Sperry RW: Some functional effects of sectioning the cerebral commissures in man. Proc Natl Acad Sci USA 48:1765-1769, 1962

8. Gazzaniga MS, Bogen JE, Sperry RW: Laterality effects in somesthesis following cerebral commissurotomy in man. Neuropsychologia 1:209-215, 1963

9. Gazzaniga MS, Bogen JE, Sperry RW: Observations on visual perception after disconnexion of the cerebral hemispheres in man. Brain 88:221, 1965

10. Gazzaniga MS, Bogen JE, Sperry RW: Dyspraxia following division of the cerebral commissures. Arch Neurol 16:606612,1967

11. Gazzaniga MS, LeDoux JE: The Integrated Mind. New York, Plenum Press, 1977

12. Gazzaniga MS, LeDoux JE, Wilson DH: Language, praxis, and the right hemisphere: clues to some mechanisms of consciousness. Neurology (Minneap) (in press)

13. Glass AV, Gazzaniga MS, Premack D: Artificial language training in global aphasics. Neuropsychologia 11:95-103, 1973

14. Jenkins J, Russell WA, Succi GJ: An attas of semantic profiles for 360 words. Am J Psychol 71:688-699, 1958

15. LeDoux JE, Wilson DH, Gazzaniga MS: Manipulo-spatial aspects of cerebral lateralization. Neuropsychologia (in press)

16. Levy J: Psychobiological implications of bilateral asymmetry, in Dimond SJ, Beaumont JG (eds): Hemisphere Function in the Human Brain. New York, Halstead Press, 1974

17. Levy-Agresti J, Sperry RW: Differential perceptual capacities in major and minor hemispheres. Proc Natl Acad Sci USA 61:1151, 1968

18. Mackay D: Discussion of Sperry [26]

19. Mackay D: Personal communication cited in Gazzaniga [5]

20. Milner B, Taylor L: Right hemisphere superiority in tactile patrern-recognition after cerebral commissurotomy: evidence for nonverbal memory. Neuropsychologia 10:1-15, 1972

21. Nebes R: Superiority of the minor hemisphere in commissurotomized man for the perception of part-whole relations. Cortex 7:333-349, 1971

22. Nebes R: Dominance of the minor hemisphere in commissurotomized man on a test of figural unification. Brain 95:633-638, 1972 
23. Nebes R: Perception of spatial relationships by the right and left hemispheres of commissurotomized man. Neuropsychologia 11:285-289, 1973

24. Nebes R: Hemisphere specialization in commissurotomized man. Psychol Bull 81:1-14, 1974

25. Ornstein R: Lateral specialization in normals. Presented at the New York Academy of Sciences, November, 1976

26. Sperry RW: Brain bisection and consciousness, in Eccles JC (ed): Brain and Conscious Experience. New York, Springer, 1966

27. Sperry RW: Mental unity following surgical disconnection of the hemispheres. Harvey Lect 62:293-323, 1967

28. Sperry RW: Hemisphere deconnection and unity in conscious awareness. Am Psychol 23:723-733, 1968
29. Sperry RW: A modified concept of consciousness. Psychol Rev $76: 532-536,1969$

30. Sperry $R W$ : Lateral specialization in the surgically separated hemispheres, in Schmitt FO, Worden FG (eds): The Neurosciences Third Study Program. Cambridge, MA, MIT Press, 1974

31. Wilson DH, Reeves A, Gazzaniga MS, et al: Cerebral commissurotomy for the treatment of intractable seizures. Neurology (Minneap) (in press)

32. Zaidel E, Sperry RW: Performance on the Raven's colored progressive matrices test by commissurotomy patients. Cortex 9:34-39, 1973

33. Zangwill $O L$ : Consciousness and the cerebral hemisphere, in Dimond SJ, Beaumont JG (eds): Hemisphere Function in the Human Brain. New York, Halstead Press, 1974 